of iodophor vs iodine tincture skin preparation on blood culture contamination rate. JAMA 1993;269:1004-1006.

10. Mirrett $S$, Weinstein MP, Reimer LG, et al. Relevance of the number of positive bottles in determining clinical significance of coagulase-negative staphylococci in blood cultures. J Clin Microbiol 2001;39:3279-3281.

Christine Geffers, MD University Medicine Berlin Berlin, Germany

Barry M. Farr, MD, MS University of Virginia Charlottesville, Virginia

\section{Bacteremia Due to Streptococcus agalactiae}

\section{To the Editor:}

Streptococcus agalactiae bacteremia is common in neonates and sometimes occurs in females after obstetric or gynecologic surgery. However, it is unusual in males. ${ }^{1}$ During a 3-year prospective survey of streptococcal bacteremia in three university hospitals in the Slovak Republic, we analyzed 32 cases of $S$. agalactiae bacteremia; data are summarized in the table. Twenty occurred in neonates and 12 in patients 24 to 82 years old. Surprisingly, 9 of the patients were male, and only 4 of them had identified risk factors (dialysis, 2; abdominal surgery, 2). The other five males had no underlying risk factors for bacteremia. They had been healthy and had not been in other hospitals. The 20 neonates with bacteremia were presumably infected at birth, despite implementation of the 1990 guidelines for prevention of $S$ agalactiae bacteremia.

Six of the 32 patients had bacteremia due to erythromycin-resistant, 2 due to trimethoprim/sulfamethoxazole-resistant, and 6 due to doxycycline-resistant strains. One strain isolated from blood culture was penicillin resistant (minimum inhibitory concentration, $0.5 \mu \mathrm{g} / \mathrm{mL}$ ). Six of the 32 patients died, all of whom were

TABLE

RISK FACTORS AND OUTCOMES OF STREPTOCOCCUS AGALACTLAE BACTEREMIA IN THE 32 PATIENTS

\begin{tabular}{lccc}
\hline Factor & $\begin{array}{c}\text { All Patlents } \\
(\mathbf{N}=\mathbf{3 2})\end{array}$ & $\begin{array}{c}\text { No. (\%) of } \\
\text { Neonates } \\
(\mathbf{n = 2 0 )}\end{array}$ & $\begin{array}{c}\text { No. (\%) of } \\
\text { Others } \\
(\mathbf{n}=\mathbf{1 2})\end{array}$ \\
\hline Male & 18 & $9(45)$ & $9(75.0)$ \\
Diabetes & 4 & $0(0)$ & $4(33.3)$ \\
Age $>$ 65 $y$ & 7 & $0(0)$ & $7(58.8)$ \\
Catheter & 24 & $19(95)$ & $5(43.0)$ \\
Dialysis & 2 & $0(0)$ & $2(17.0)$ \\
Surgery & 5 & $0(0)$ & $5(41.6)$ \\
Ventilator & 8 & $6(30)$ & $2(17.0)$ \\
Previous antibiotic therapy & 6 & $5(25)$ & $1(8.3)$ \\
Gestational age $<32$ weeks & 6 & $6(30)$ & $0(0.0)$ \\
Birth weight $<1,500 \mathrm{~g}$ & 6 & $6(30)$ & $0(0.0)$ \\
Erythromycin resistant & 6 & $2(10)$ & $4(33.3)$ \\
TETs and TMP/SMX resistant & 2 & $2(10)$ & $0(0.00)$ \\
Complications & 2 & $0(0)$ & $2(17.0)$ \\
Death & 6 & $6(30)$ & $0(0.0)$ \\
\hline
\end{tabular}

TETs = tetracyclines; TMP/SMX = trimethoprim/sulfamethoxazole.

neonates with very low birth weights $(<1,500 \mathrm{~g})$. The attributable mortality rate was $18.5 \%$. In comparison of our results with those of the largest $S$. agalactiae bacteremia study, which included 41 cases from Spain, ${ }^{2}$ the rates of erythromycin resistance were similar. Penicillin resistance was not observed in the Spanish study, despite high rates of penicillin resistance in pneumococci and viridans streptococci in Spain. We have no explanation for 12 cases with no risk factors leading to $S$. agalactiae bacteremia in patients other than neonates and women. Five of the nine male patients were young and previously healthy without a history of urinary tract infection. More studies on $S$. agalactiae are needed.

\section{REFERENCES}

1. Schuchat A. Group G Streptococcus agalactiae. Lancet 1999;353:51-56.
2. Alós JI, Aracil B, Oteo J, et al. High prevalence of erythromycin-resistant, clindamycin/miocamycin-susceptible (M-phenotype) Streptococcus pyogenes: results of a Spanish multicentre study in 1998. J Antimicrob Chemother 2000;45:605-609.

Marianna Mrazova, MD, PhD

Postgraduate Medicine School Bratislava, Slovak Republic Vladimir Kremery, Jr., MD, DSc, FACP,

FRCP

Margareta Kacmarikova, PhD, ME School of Health Trnava University Trnava, Slovak Republic

Jadwiga Fargasova, PharmD, PhD Department of Clinical Pharmacology Kosice, Slovak Republic Andrea Docze, MD, PhD Pavol Beno, PharmD, PhD School of Health Trnava University Trnava, Slovak Republic 


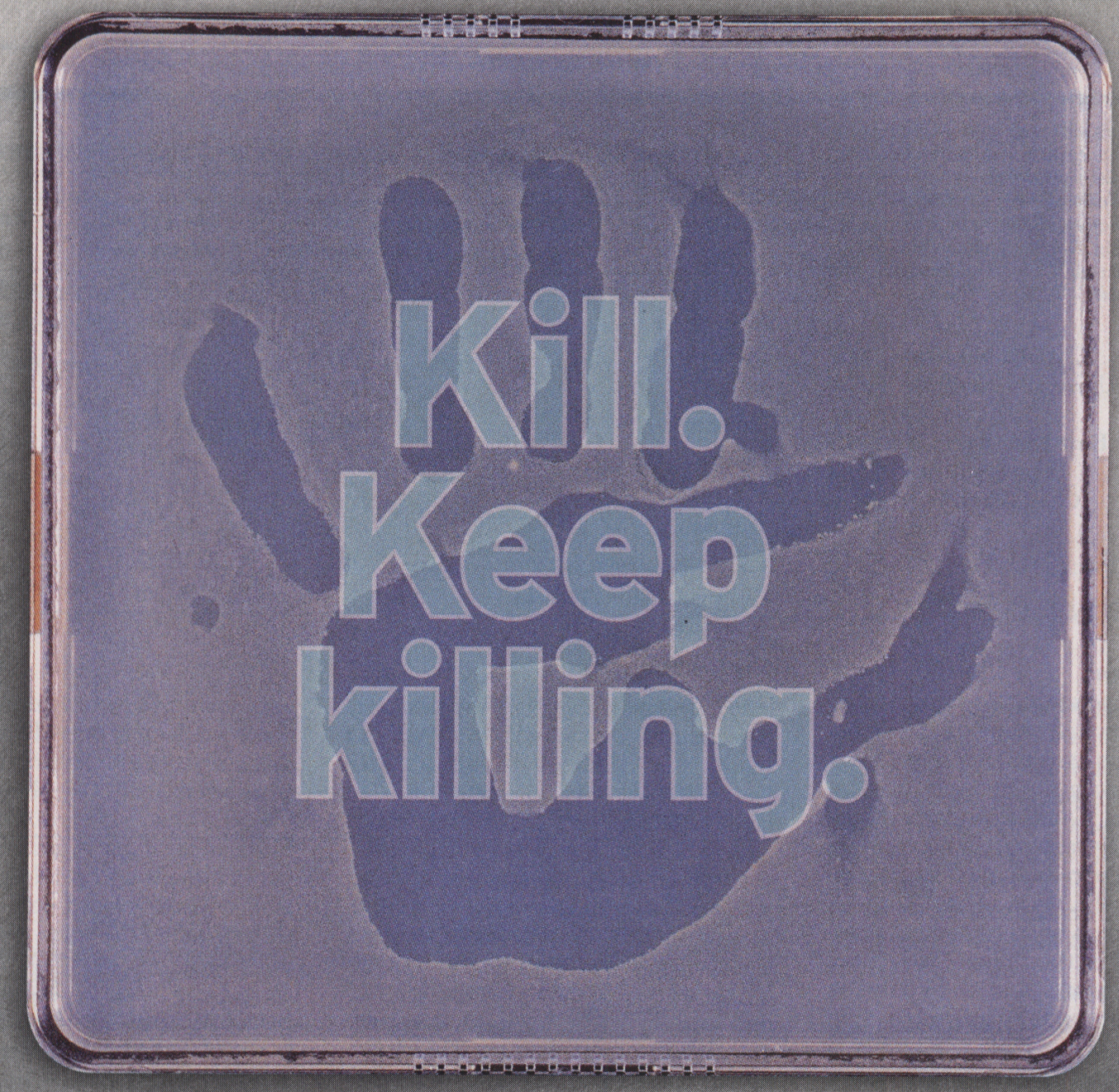

\section{For persistent antiseptic activity, you're in the clear with Hibiclens.}

Clinical studies* have proven the efficacy and persistence of Hibiclens, demonstrating how it goes to work on germs and provides a cumulative effect that continues to kill germs long after your shift is over.

The most recent study observed agar plates that were inoculated with staph aureus. Hands were washed with Hibiclens, and then pressed onto the inoculated plates - palms down. The plates were then incubated and a whitish film of staph aureus grew in areas not affected by Hibiclens.
Hibiclens, armed with its $4 \%$ Hibitane (CHG) formulation immediately killed germs and displayed a cumulative effect that didn't know when to quit. In fact, this demonstration showed the antiseptic still killing on the fifth day of use and 6 hours after the final daily handwash.**

\section{Immediately kill and keep} killing germs with Hibiclens. For more information, call 1-800-843-8497.

*Test on file.

The persistence of Hibiclens provides extra protection. Recommended antiseptic procedures of your institution should be followed when using Hibiclens.

**The darker color in the hand print shows the cumulative effect of Hibiclens on staph aureus, the fifth day of use 6 hours after the final daily handwash. 